G155(P) CHANGING HEARTS AND MINDS? GP PRACTICES AND YOUNG PEOPLE MAKING CHANGE HAPPEN TOGETHER

${ }^{1} \mathrm{M}$ Cheetham, ${ }^{2} \mathrm{E}$ Nixon, ${ }^{2} \mathrm{~J}$ Percival, ${ }^{3} \mathrm{~B}$ Davison, ${ }^{4} \mathrm{~A}$ Ellins. ${ }^{1} \mathrm{Health}$ and Social Care Institute, Teesside University, Middlesbrough, UK; ${ }^{2}$ Changemakers, The Foyer Federation, Newcastle-Upon-Tyne, UK; ${ }^{3}$ Involvement and Service Development Team, Northumbria Healthcare NHS Trust, Morpeth, UK; ${ }^{4}$ Health Improvement Team, Newcastle Hospital Community Health, Newcastle-Upon-Tyne, UK

\subsection{6/archdischild-2015-308599.151}

Aims $75 \%$ of adult mental health problems appear in adolescence, but young people report difficulties accessing appropriate health services. GP practices are not always seen as responsive, and barriers to access are reported by young people. Greater understanding is required of the benefits, pitfalls and possibilities of young people's engagement in general practice. This study examines the effects of a collaborative, peer led intervention to improve primary health care for young people with mental health concerns.

Methods Focus group discussions were held with young people trained as Changemakers, to explore the reported benefits and risks of volunteering. 1:1 interviews were conducted with representatives from partner organisations, GPs and practice managers to explore what difference, if any, young people's input had made, for whom, and how.

Results Our findings demonstrate the potential of the programme, including You're Welcome, to drive positive changes in general practice, led by young people, supported by voluntary sector partners. We outline the challenges and opportunities of the Changemakers model and the factors influencing its success, including the support and guidance required. We report young people's suggestions for new ways of working, their ideas for engaging young people, and recommendations for health service delivery.

Conclusions Traditional models of patient involvement do not work with young people. This peer-led intervention offers a promising alternative, stimulating practical and attitudinal changes in the delivery of young people friendly primary care. It requires whole practice investment of time and resources, and a willingness to embrace change. The resulting efforts to encourage access by young people, including those with mental health problems, will potentially benefit the wider practice population.

\section{G156(P) MOVING FROM CHILD TO ADULT HEALTH CARE: DEVELOPMENT OF BENCHMARKS FOR TRANSITION}

${ }^{1} S$ Aldiss, ${ }^{2} \mathrm{~L}$ Rose, ${ }^{3,4} \mathrm{H}$ Cass, ${ }^{4} \mathrm{~J}$ Ellis, ${ }^{1,5} \mathrm{~F}$ Gibson. ${ }^{1}$ Department of Children's Nursing, London South Bank University, London, UK; '2University College London Hospital NHS Foundation Trust, London, UK; ${ }^{3}$ Evelina London Children's Hospital, London, UK; ${ }^{4}$ Royal College of Paediatrics and Child Health, London, UK; ${ }^{5}$ Great Ormond Street Hospital for Children NHS Foundation Trust, London, UK

\subsection{6/archdischild-2015-308599.152}

Background Transition from child to adult health care for young people with long-term conditions is currently a 'hot topic' within the NHS. In spite of the growing evidence base, the implementation of transitional care remains a challenge. Lack of being prepared' was a main finding from young people and parents reported by the Care Quality Commission (CQC) in 2014. Here only $54 \%$ of young people described preparation for transition that had enabled them to be involved in the process and $80 \%$ of pre-transition case notes reviewed had no transition plans for health. The CQC recommend that existing good practice guides be followed to ensure young people are properly supported through transition. Benchmarks offer a guide/standards that services can measure themselves against to see how they are doing, where they could improve and can facilitate the sharing of best practice.

Aims To describe the development of a clinical practice-benchmark tool for transition.

Method This qualitative study involved focus groups, workshops and interviews. Data were collected from young people with long-term health conditions, their parents, professionals and experts leading on transition within the UK. Transcripts were analysed using qualitative content analysis. The focus was to develop an increased understanding of transition, from multiple perspectives, and to describe what strategies and resources might be required to facilitate transition with the aim of developing a benchmark tool.

Results For young people and their parents/carers to experience timely and effective transition 8 factors and their associated indicators of best practice statements have been developed from the data: young people and parents led on selecting the factors and practice statements. Communication, co-ordination, gradual transition and support to manage their health condition as an adult were paramount for them. The tool was distributed to a range of professionals across the UK for comment and subsequently refined to produce the current benchmarks.

Conclusion The need for change, in order to best meet the needs of young people, and parents during transition is very evident. This paper will describe the development of benchmarks for transition, which indicate young people and parents' needs and preferences regarding transition to adult care.

\section{G157(P) LOCATION OF CARE FOR TEENAGERS IN HOSPITAL: A STAFF PERSPECTIVE}

${ }^{1} \mathrm{~A}$ Yeadon, ${ }^{2} \mathrm{~J}$ Mannion. 'School of Paediatrics, Health Education Yorkshire and the Humber, Leeds, UK; ${ }^{2}$ Children's Ward, York Teaching Hospital NHS Foundation Trust, York, UK

\subsection{6/archdischild-2015-308599.153}

Aims Deciding whether a young person should be admitted to a paediatric or adult ward is not always an easy judgement. In a district general hospital with a fairly flexible admission policy, which includes living an 'adult lifestyle' as suggesting admission to an adult ward, we sought the views of both referring and receiving staff. This was part of a wider project aimed at encouraging patient choice when determining location of care.

Methods Two questionnaires were distributed, using an anonymous online survey tool, to:

1. Referring staff in primary care and the emergency department (38 responses)

2. Receiving staff working on the paediatric ward and adult admissions wards (71 responses)

Results Both referring and receiving staff were unclear about current admission guidance.

Referring staff reported the most important factors in choice of ward were age, emotional maturity, safety of other patients and whether the patient was already known to a consultant. Least important were staffing levels and bed availability. Similar opinions were expressed by receiving staff, although not surprisingly they placed more importance on adequate staffing levels.

$94 \%$ of referrers reported that patient choice was fairly/very important, but only 55\% regularly sought the young person's preference. 